\title{
Eficácia das Intervenções do Banco Central do Brasil sobre a Volatilidade Condicional da Taxa de Câmbio Nominal*
}

\author{
Fernando Nascimento de Oliveira ${ }^{\dagger}$, Alessandra Plaga ${ }^{\ddagger}$
}

\author{
Contents: 1. Introdução; 2. Dados; 3. o Modelo da Volatilidade Condicional da Taxa de \\ Câmbio Nominal; 4. Análise Empírica; 5. Conclusão. \\ Keywords: Intervenções, Taxa de Câmbio, Volatilidade, Banco Central do Brasil. \\ JEL Code: F58, E52, F31.
}

Este artigo tem como objetivo analisar a eficácia dos instrumentos de intervenção utilizados pelo Banco Central do Brasil sobre a volatilidade condicional da taxa de câmbio nominal. Como ferramenta de intervenção, o Banco Central do Brasil utiliza instrumentos padrões da literatura, tais como taxa de juros e intervenções no mercado spot, e intervenções pouco usuais como títulos públicos indexados ao dólar e derivativos de câmbio como swaps cambiais. Modelamos a volatilidade condicional da taxa de câmbio por meio do modelo E-GARCH de Nelson e CAo (1992). Utilizamos base de dados diária da taxa de câmbio nominal e das intervenções para o período de janeiro de 1999 a setembro de 2006. Nossos resultados mostram que em todos os períodos, inclusive nos períodos com crise cambial, alguma forma de intervenção afetou a volatilidade condicional da taxa de câmbio nominal.

This paper analyzes the effectiveness of instruments of intervention used by the Central Bank of Brazil over the conditional volatility of the nominal exchange rate. Central Bank of Brazil used as intervention instruments, standard instruments of the literature - such as interest rate and interventions in the spot market, and unusual instruments - such as public bonds indexed to the dollar and foreign exchange rates swaps. The conditional volatility of the exchange rate was modeled using an E-GARCH model, Nelson e CAo (1992). We used daily data of nominal exchange rate and the interventions for the period from January of 1999 to September of 2006. Our results showed that in all sample periods we study, including the ones with

\footnotetext{
*As opiniões e conclusões expressas no texto são de inteira responsabilidade dos autores. De maneira alguma, este artigo reflete as opiniões oficiais do Banco Central do Brasil sobre o tema.

${ }^{\dagger}$ Banco Central do Brasil e IBMEC/RJ. E-mail: fernando.nascimento@bcb.gov.br

${ }^{\ddagger}$ IBMEC/RJ. E-mail: aplaga@petrobras.com.br
} 
currency crisis, some instrument of intervention affected the conditional volatility of the nominal exchange rate.

\section{INTRODUÇÃO}

Em um regime de taxa de câmbio flutuante, teoricamente não deveriam ocorrer intervenções no mercado cambial, visto que o mercado deveria determinar a taxa nominal de equilíbrio, baseado em movimentos de oferta e demanda por moeda estrangeira. Entretanto, os bancos centrais fazem intervenções no mercado de câmbio para corrigir tendências, diminuir a volatilidade cambial e acalmar os mercados em momentos de crise. ${ }^{1}$

Entre janeiro de 1999 e dezembro de 2006, o Banco Central do Brasil utilizou diversos instrumentos de intervenção no mercado cambial. Ele utilizou instrumentos tradicionais como compra e venda de moeda estrangeira no mercado à vista e taxa de juros. Ao mesmo tempo, utilizou outros instrumentos não tradicionais, que são derivativos da taxa de câmbio nominal, como títulos públicos indexados ao dólar e swaps cambiais.

Algumas perguntas surgem naturalmente: Será que os instrumentos foram eficazes para afetar a volatilidade condicional da taxa de câmbio nominal nesse período? Em particular, será que foram eficazes quando ocorreram as duas crises cambiais do período, no primeiro semestre de 1999 e no segundo semestre de 2002 ? O objetivo deste artigo é responder estas perguntas. ${ }^{2}$

Utilizando dados diários de intervenções no mercado de câmbio e empregando o modelo E-GARCH $(1,1)$ de Nelson e CAo (1992), estimamos o modelo de volatilidade condicional da taxa de câmbio nominal para os períodos com crise cambial e para os períodos sem crise cambial incorporando as diversas intervenções do Banco Central no mercado de câmbio. ${ }^{3}$

Nossos resultados mostram que no primeiro período de crise cambial, no primeiro semestre de 1999, o Banco Central adicionou volatilidade à taxa de câmbio nominal por meio das intervenções à vista. No segundo período de crise cambial, correspondente à fase pré-eleitoral do governo Lula no segundo semestre de 2002, as intervenções do Banco Central via títulos cambiais reduziram a variância condicional da taxa de câmbio nominal. Nos períodos sem crise cambial, um ou outro instrumento de intervenção foi eficaz. ${ }^{4}$

Uma possível explicação para nossos resultados pode estar relacionada à implementação por parte do Banco Central do Brasil, após a primeira crise cambial, de um conjunto de políticas macroeconômicas - como sistema de metas de inflação, regime de câmbio flutuante entre outras - que aumentaram sua credibilidade junto ao mercado. Como consequência, aumentou a eficácia dos instrumentos de intervenção cambial. Isto permitiu que o Banco Central do Brasil sinalizasse melhor, por meio de suas intervenções no mercado cambial, sua futura política monetária.

\footnotetext{
${ }^{1}$ Um aumento da volatilidade cambial pode provocar perda de bem estar, conforme Obstfeld (1988) e Rogoff (1984) mostram, pois as pessoas são avessas a flutuações no consumo e preferem uma renda constante ao longo do tempo. Essa perda pode variar de acordo com a dependência do país em relação ao comércio internacional, ou seja, quando depende fortemente das suas exportações ou se depende mercado financeiro internacional, quando o país depende da venda de títulos da dívida pública no mercado externo, o que não é o caso de economias desenvolvidas. Países emergentes dependem fortemente destes dois fatores, o que faz com que a volatilidade cambial tenha um custo demasiadamente elevado no desempenho de suas economias.

${ }^{2}$ Como Dominguez (1993) e Sarno e Taylor (2001) mostram o Banco Central pode estar interessado em intervir tanto para aumentar como para diminuir a volatilidade cambial em períodos sem crise cambial. É claro que em períodos de crise cambial, o Banco Central será eficaz com suas intervenções se diminuir a volatilidade condicional da taxa de câmbio.

${ }^{3}$ Nosso objetivo ao usar um E.GARCH e não um GARCH foi o de poder analisar separadamente tanto os efeitos de intervenções que aumentam (positivas) ou diminuem (negativas) o estoque de ativos cambiais em poder do mercado. Modelos GARCH não conseguem fazer isto.

${ }^{4}$ Todos os nossos resultados se mostram robustos a diferentes especificações do modelo de volatilidade condicional da taxa de câmbio nominal.
} 
Nosso artigo se situa em uma vasta literatura empírica sobre o tema. ${ }^{5}$ Os resultados encontrados não são conclusivos, visto que variam de acordo com o período analisado e com as estratégias de intervenção utilizadas. A maior parte da literatura investiga as intervenções do banco central realizadas na economia norte-americana, alemã e japonesa. Portanto, existem poucos trabalhos que estudam esses movimentos para os mercados emergentes, em particular o Brasil. ${ }^{6,7}$ No caso brasileiro podemos destacar o trabalho de Araújo e Goldfajn (2004).

Araújo e Goldfajn (2004) $)^{8}$ investigaram os efeitos das intervenções do Banco Central brasileiro no mercado de câmbio no período de 2000 a 2003. Eles utilizaram o modelo E-GARCH $(1,1)$ de Nelson e CAo (1992) para estimar o efeito das intervenções tanto no retorno quanto na variância condicional da taxa de câmbio. Em seguida adotaram a metodologia de Vella (1993) para investigar a endogeneidade das intervenções. Concluíram que as intervenções adicionaram volatilidade à taxa de câmbio. Mas ao levar em conta a questão da endogeneidade obtiveram conclusões opostas.

No caso da literatura internacional, Dominguez (1993) concluiu que as políticas de intervenção sempre influenciam a variância condicional da taxa de câmbio e dependendo do tipo de intervenção pode haver diferentes efeitos sobre a volatilidade. Intervenções ocultas ${ }^{9}$ aumentam a volatilidade da moeda, enquanto que aquelas tornadas públicas, durante o período de análise, levaram a uma redução da volatilidade.

O restante deste artigo está organizado da seguinte forma: Na Seção 2, descrevemos a base de dados. Na Seção 3, descrevemos o modelo da volatilidade condicional da taxa de câmbio nominal. Na Seção 4, apresentamos os resultados da análise empírica. Na Seção 5, concluímos.

\section{DADOS}

Nesta seção, iremos apresentar a base de dados utilizada, as variáveis que compõe o nosso modelo empírico e iremos descrever como dividimos o período de análise. O modelo utilizado será apresentado na próxima seção. As variáveis explicativas da volatilidade da taxa de câmbio (R\$/US\$) são: a taxa de câmbio defasada em um período, a taxa de juros doméstica (em p.p. ao ano), as intervenções do Banco Central no mercado de câmbio por meio do mercado à vista, de swaps e de títulos cambiais (em milhões de dólares). Os dados estão em bases diárias e compreendem o período de 01/01/1999 à 21/09/2006.

\subsection{Período de Análise}

O Banco Central somente começou a divulgar as datas intervenção no mercado à vista a partir de julho de 1999. Caso nosso estudo começasse somente em julho, perderíamos o período imediatamente após a mudança do regime cambial (janeiro de 1999 a junho de 1999) que é bastante rico sobre o

\footnotetext{
${ }^{5}$ Sarno e Taylor (Ver 2001).

${ }^{6}$ Os estudos empíricos sobre a eficácia das intervenções em economias emergentes podem divergir dos resultados dos estudos sobre as economias desenvolvidas. Essa diferença deve-se à complexidade dos regimes cambiais, à sofisticação do mercado e aos sistemas regulatórios das transações com o exterior.

${ }^{7}$ As políticas cambiais adotadas pelos bancos centrais de economias em desenvolvimento também diferem das economias industriais, pois possuem diferentes objetivos, como por exemplo: favorecimento da competitividade das exportações e o influxo de capitais estrangeiros. As economias em desenvolvimento também tendem a tolerar uma maior volatilidade nas reservas internacionais, taxa de juros doméstica e preço das commodities que nas taxas de câmbio. Isso corre, pois quando o grau de abertura da economia é pequeno e há grande concentração dos agentes, é provável que a taxa de câmbio seja bastante volátil caso as autoridades monetárias não sejam bastante atuantes (Domaç e Mendonza, 2002).

${ }^{8}$ Nosso artigo difere do artigo de Araújo e Goldfajn (2004), visto que utilizamos um período amostral maior e consideramos mais instrumentos de intervenção utilizados pelo Banco Central do Brasil como variáveis explicativas da volatilidade da taxa de câmbio nominal.

${ }^{9}$ Oculta foi o termo usado pelos autores para definir as intervenções que não são publicamente anunciadas ao mercado pelos Bancos Centrais.
} 
ponto de vista de volatilidade cambial e possui fortes indícios de intervenção no mercado à vista. Desta maneira, consideramos que houve intervenção em todos os dias que antecederam a data de 01/07/1999 e a partir de então, consideramos as datas anunciadas e divulgadas pelo Banco Central do Brasil. Dividimos nossa amostra em períodos com crises cambiais e períodos sem crises cambiais, uma vez que o resultado da intervenção pode variar dependendo do período de análise. Segue abaixo a descrição dos períodos analisados conforme mostramos na Tabela 1:

Table 1: Período de Análise

\begin{tabular}{lcrcc}
\hline & Início & Fim & Crise Cambial & $\mathrm{N}^{\text {o }}$ de Observações \\
\hline Período A & $01 / 01 / 99$ & $30 / 06 / 99$ & Sim & 124 \\
Período B & $01 / 07 / 99$ & $30 / 05 / 02$ & Não & 743 \\
Período C & $31 / 05 / 02$ & $31 / 12 / 02$ & Sim & 151 \\
Período D & $01 / 01 / 03$ & $31 / 12 / 03$ & Não & 259 \\
Período E & $01 / 01 / 04$ & $21 / 09 / 06$ & Não & 700 \\
\hline TOTAL & $01 / 09 / 99$ & $21 / 09 / 06$ & & 1977 \\
\hline
\end{tabular}

O horizonte de estimação é de janeiro de 1999 a setembro de 2006. Os dados são diários. Os períodos estimados são: todo período, os períodos sem crise cambial (julho de 1999 a maio de 2002, janeiro de 2003 a setembro de 2006) e os períodos com crises cambiais (janeiro de 1999 a junho e 1999 e maio de 2002 a dezembro de 2002).

O Período A é o primeiro período de crise cambial da nossa amostra, possui 124 observações e começa em janeiro de 1999 e termina em junho de 1999. Destacamos neste período a decisão pela livre flutuação da taxa de câmbio, ocorrida em janeiro e a unificação das posições de câmbio dos segmentos Livre e Flutuante. O primeiro trimestre de 1999 foi marcado por uma grande volatilidade mundial, com forte movimento de saída de capitais estrangeiros, especialmente no mês de janeiro. Período com quedas históricas do índice BOVESPA, queda de preço dos títulos soberanos do Brasil e redução drástica da credibilidade do país. No segundo trimestre de 1999, percebemos uma melhora nas condições de liquidez de divisas e a taxa de câmbio mostrou comportamento bem mais estável. O país passou a emitir sinais consistentes de recuperação dos sobressaltos trazidos pelos desdobramentos da crise russa e melhoravam sistematicamente as perspectivas sobre os reais efeitos da mudança do regime cambial na economia brasileira.

O Período B foi relativamente tranquilo, possui 743 observações e se inicia no mês de julho/1999 e termina em maio/2002. Após a desvalorização do Real frente à moeda norte-americana - que ultrapassou 59\% nos nove primeiros meses do ano de 1999 - o que mais influenciou o nervosismo observado nos mercados de câmbio e de juros no período foram fatores externos, que acabaram se sobrepondo à melhoria das condições econômicas observada no ambiente interno.

O Período C compreende a fase pré-eleitoral do Governo Lula, que começa em 31/05/2002 e termina em 31/12/2002 e é o segundo período de crise cambial em nossa amostra, com 151 observações. O aumento das intenções de voto para o candidato de oposição ao governo brasileiro provocou uma maior demanda por dólares e a taxa de câmbio apresentou seu maior nível histórico desde o Plano Real. Havia um temor que o governo Lula descontinuasse a ortodoxia fiscal e monetária implementada pelo governo anterior e com o rebaixamento da posição do Brasil nas agências internacionais de classificação de risco, os agentes passaram a reduzir a sua exposição a títulos da dívida externa brasileira.

Os Períodos D e E representam uma fase de redução da aversão a risco e representa o período de maior estabilidade econômica do país e totalizam 959 observações. O Período D contempla o primeiro ano do Governo Lula (01/01/03 a 31/12/03) e ele foi destacado devido ao fato de que a política de intervenções do Banco Central e a percepção do mercado sobre o novo Governo ainda sofriam grandes 
alterações. O Período E inicia em 01/01/04 e termina em 21/09/06. A condução da política econômica manteve a estabilidade de preços, assegurou o crescimento sustentado do país, reduziu dívida cambial e recompôs o nível de reservas internacionais. Período de economia interna pujante, menor aversão ao risco de investidores em relação aos países emergentes, elevada liquidez internacional e alto preço das commodities. O risco-país emitido pela EMBI manteve ao longo do ano trajetória declinante, aproximando-se do grau de investimento.

\subsection{Taxa de Câmbio Nominal}

Os dados da taxa de câmbio nominal são diários e utilizamos a cotação de fechamento do dólar comercial em reais na ponta de compra. Os dados foram extraídos do Sisbacen e conforme demonstrado na Figura 1, a série possui tendência. Ao fazermos o Teste de Raiz Unitária, percebemos que esta tendência é estocástica (valor crítico pelo teste Elliott-Rothenberg-Stock DF-GLS igual a -0,89). Para transformar a série em estacionária, ou seja, sem tendência, iremos utilizar a primeira diferença do logaritmo da taxa de câmbio. Analisando o histograma da taxa de câmbio, Tabela 2, percebemos que a série possui coeficiente de achatamento (curtose) igual a 17,61; coeficiente de assimetria (skewness) igual a 0,37; média igual a 0,00 e desvio-padrão igual a 0,01 para o período de janeiro/99 a setembro/06. Esses valores nos indicam que estamos perante de uma série temporal que não segue uma distribuição normal, o que pode ser comprovado pelo teste Jarque-Bera, cujo $p$-valor igual a 0,00 , nos sugere rejeitar a hipótese nula de normalidade. Em nosso modelo, a variação diária do logaritmo da taxa de câmbio será a variável dependente, enquanto a sua defasagem de um período será uma das variáveis explicativas, vide que pelo correlograma dos resíduos percebemos que o modelo é do auto-regressivo de ordem 1 $(\operatorname{AR}(1))$.

Figure 1: Taxa de câmbio nominal

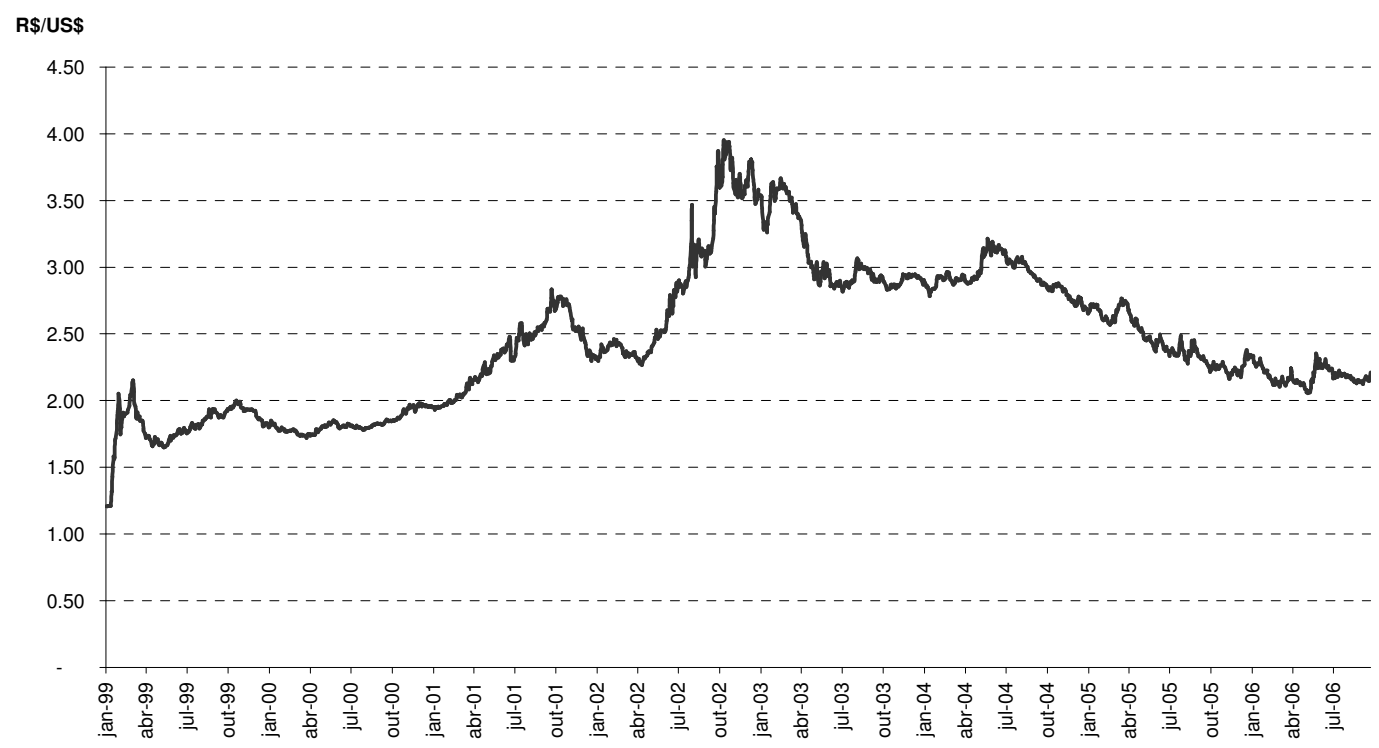


Table 2: Estatística Descritiva da Taxa de Câmbio Nominal

\begin{tabular}{lr}
\hline Estatística descritiva & Valor \\
\hline Média & 0.000306 \\
Mediana & 0.000000 \\
Desvio-Padrão & 0.011566 \\
Assimetria & 0.368704 \\
Curtose & 17.60768 \\
Jarque-Bera & 17613.40 \\
Probabilidade & 0.000000 \\
\hline
\end{tabular}

Analisamos a taxa de câmbio nominal para todo o período de nossa análise. Os dados são diários. Utilizamos a cotação de fechamento do dólar comercial em reais na ponta de compra. Pelo histograma do logaritmo da variável da possui curtose igual 17,61; média 0,00 e desvio-padrão de 0,01.

\subsection{Instrumentos de intervenção}

Iremos considerar em nosso modelo como instrumentos de intervenção do Banco Central a taxa de juros doméstica (Selic), as compras e vendas de dólares no mercado à vista, os títulos públicos atrelados ao dólar e os swaps cambias. Por convenção, definimos que a venda de dólares, ou oferta desta moeda no mercado, está indicada pelo sinal positivo, enquanto a compra de dólares pelo sinal negativo.

O Banco Central escolhe seus instrumentos de intervenção, dependendo do período, vide Tabela 3. Por exemplo, durante a mudança do regime de câmbio em 1999, o Banco Central usou com mais intensidade as intervenções no mercado à vista e a taxa de juros. Em 2001, o Banco Central usou títulos cambiais e no segundo semestre de 2002 usou mais swaps de câmbio. As intervenções foram maiores durante a crise cambial no primeiro semestre de 1999 e no segundo semestre de 2002, e praticamente inexistente no ano 2000, quando a economia de Brasil não sofreu nenhum choque pertinente.

O processo de obtenção das séries de intervenção teve as seguintes etapas:

(i) cada uma das séries deu origem a duas séries, ${ }^{10}$ separando-se as operações de compra e venda;

(ii) calculamos os desvios padrões de cada uma destas séries ;

(iii) as intervenções que apresentassem montante inferior a média mais um desvio padrão foram retiradas da amostra. ${ }^{11}$ Após a aplicação desses filtros, obtivemos as séries de intervenções utilizadas na regressão.

Definimos intervenções descontínuas $(I N T)$ como as operações de compra ou venda de moeda que fossem em módulo superior à média mais um desvio padrão, conforme descrito abaixo:

$$
|I N T| \geq \mu+\sigma
$$

a) Taxa de Juros Doméstica

A taxa de juros é considerada como uma forma de intervenção utilizada pelo Banco Central, pois impacta no fluxo de capital de câmbio exterior e afeta as dinâmicas da taxa de câmbio nominal. Na literatura, esta forma de intervenção é conhecida como o canal monetário de intervenção ou como forma esterilizada de intervenção.

\footnotetext{
${ }^{10}$ Esta premissa, utilizada em alguns textos da literatura, é totalmente arbitrada e outras hipóteses podem ser testadas para definir quais operações em mercado seriam classificadas como intervenção.

${ }^{11} \mathrm{Em}$ alguns casos desconsideramos esta condição, especialmente no mercado à vista, com o intuito de incluir na amostra os períodos de sucessivas intervenções neste mercado, por mais que as mesmas fossem inferior a média mais um desvio padrão.
} 
Table 3: Resumo das intervenções observadas por período

\begin{tabular}{ccccccc}
\hline Tipo de Intervenções & $\begin{array}{c}\text { Período (A) } \\
\text { 01/01/99 }\end{array}$ & $\begin{array}{c}\text { Período (B) } \\
31 / 05 / 02\end{array}$ & $\begin{array}{c}\text { Período (C) } \\
01 / 07 / 99\end{array}$ & $\begin{array}{c}\text { Período (D) } \\
01 / 03 / 03\end{array}$ & $\begin{array}{c}\text { Período (E) } \\
01 / 01 / 04\end{array}$ & $\begin{array}{c}\text { TOTAL } \\
01 / 01 / 99\end{array}$ \\
& $30 / 06 / 99$ & $31 / 12 / 02$ & $30 / 05 / 02$ & $31 / 12 / 03$ & $21 / 09 / 06$ & $21 / 09 / 06$ \\
\hline À Vista & 44 & 95 & 129 & 20 & 238 & 526 \\
Compra & 21 & 1 & 1 & 7 & 238 & 268 \\
Venda & 23 & 94 & 128 & 13 & 0 & 258 \\
Títulos Cambiais & 52 & 94 & 284 & 35 & 18 & 483 \\
Compra & 26 & 50 & 132 & 24 & 15 & 247 \\
Venda & 26 & 44 & 152 & 11 & 3 & 236 \\
Swaps & 0 & 37 & 3 & 41 & 84 & 165 \\
Compra & 0 & 14 & 0 & 23 & 84 & 121 \\
Venda & 0 & 23 & 3 & 18 & 0 & 44 \\
TOTAL & 96 & 226 & 416 & 96 & 340 & 1174 \\
\hline
\end{tabular}

A Tabela 3 resume a frequência de intervenções ao longo do horizonte de estimação correspondente a janeiro de 1999 a setembro de 2006 . Os dados são diários. Os tipos de intervenção são: Intervenções à Vista, Intervenções via Títulos Cambiais e Intervenções via Swaps Cambias. Os instrumentos foram separados em operações de compra e venda. Por convenção definimos que as vendas de dólares possuem sinal positivo, enquanto as compras de dólares possuem sinal negativo. Durante o período de análise foram realizadas 1.174 intervenções. Deste total 526 foram Intervenções à Vista, 483 foram Intervenções via Títulos Cambiais e 165 foram Intervenções via Swaps Cambiais.

Em nossa análise, consideramos os juros domésticos como diários e utilizamos a taxa Selic anual em pontos percentuais. Os dados foram extraídos do Sisbacen e foram transformamos tomando-se o logaritmo da série. Conforme demonstrado na Figura2, a série possui tendência e ao fazermos o Teste de Raiz Unitária, percebemos que esta tendência é estocástica (valor crítico pelo teste Elliott-Rothenberg-Stock DF-GLS igual a -2.83) e para transformar a série em estacionária, ou seja, sem tendência, precisamos utilizar a variável logaritmo da taxa de juros (Selic) em primeiras diferenças. Em nosso modelo, a variação diária do logaritmo da taxa Selic será uma variável explicativa da volatilidade condicional da taxa de câmbio nominal (R\$/US\$).

Durante a maior parte da nossa amostra, o Banco Central implementou uma política de diminuir a taxa de juros gradualmente. A exceção ocorreu no período imediatamente após a mudança no regime de câmbio no qual houve um aumento impressionante dos juros nominais.

b) Mercado à vista

Os dados das intervenções Spot foram extraídos do SGS (Sistema Gerenciador de Séries Temporais) disponível no site do Banco Central do Brasil, por meio da série de Fatores Condicionantes da base monetária - Operações com o setor externo (saldo diário). Como a Intervenção do Mercado à Vista é um dos instrumentos de intervenção utilizado pelo Banco Central, logo será uma variável explicativa da volatilidade do câmbio (R\$/US\$) em nosso modelo. Nota-se que o Banco Central do Brasil adota um padrão de cluster para tal tipo de intervenção, já que as datas em que há intervenção são sucessivas e concentradas. O motivo pelo qual ele adota esta estratégia deve-se ao fato de que os grandes movimentos de volatilidade cambial possuem elevada probabilidade de serem seguidas por variações ainda maiores da taxa de câmbio nominal. Pelo Teste de Raiz Unitária, percebemos que esta tendência é determinística (valor crítico pelo teste Elliott-Rothenberg-Stock DF-GLS igual a -5.29), logo não foram necessárias transformações.

Podemos perceber que durante os períodos de crise cambiais, Períodos A (01/01/1999 a 30/06/1999) e C (31/05/2002 a 31/12/2002) da nossa amostra, quando houve forte depreciação do Real frente ao Dólar, 
Figure 2: Taxa de juros doméstica

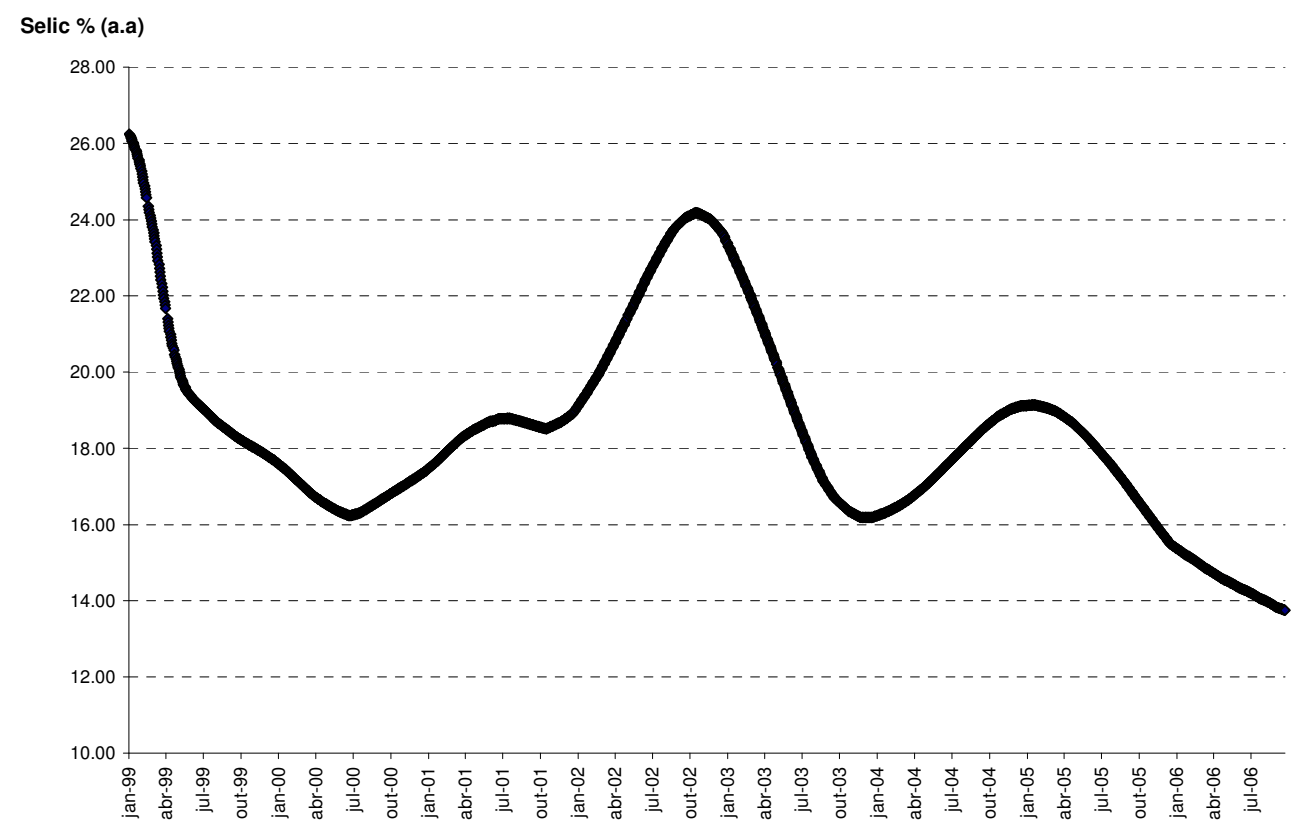

o Banco Central aumentou a oferta da moeda americana no mercado. No primeiro semestre de 1999 , foram vendidos ao mercado R\$ 156 bilhões e comprados R\$ 15 bilhões. Nos meses de maio a dezembro de 2002, o total vendido ao mercado foi R 290 bilhões e comprados R\$ 126 milhões. A partir de 2005, o Banco Central intensificou as ações de compra de dólares, visando aumentar as Reservas Internacionais e diminuir a exposição do país à moeda americana.

Table 4: Intervenções à Vista no Mercado de Câmbio

\begin{tabular}{|c|c|c|c|c|c|c|}
\hline \multirow[t]{3}{*}{ Tipo de Intervenções } & Período (A) & Período (B) & Período $(C)$ & Período (D) & Período (E) & TOTAL \\
\hline & $01 / 01 / 99$ & $31 / 05 / 02$ & 01/07/99 & $01 / 03 / 03$ & $01 / 01 / 04$ & $01 / 01 / 99$ \\
\hline & $30 / 06 / 99$ & $31 / 12 / 02$ & $30 / 05 / 02$ & $31 / 12 / 03$ & $21 / 09 / 06$ & $21 / 09 / 06$ \\
\hline À Vista & 44 & 95 & 129 & 20 & 238 & 526 \\
\hline Compra & 21 & 1 & 1 & 7 & 238 & 268 \\
\hline Venda & 23 & 94 & 128 & 13 & 0 & 258 \\
\hline
\end{tabular}

A Tabela 4 resume a frequência de Intervenções à Vista ao longo do horizonte de estimação correspondente a janeiro de 1999 a setembro de 2006 . Os dados são diários. Os instrumentos foram separados em operações de compra e venda. Por convenção definimos que as vendas de dólares possuem sinal positivo, enquanto as compras de dólares possuem sinal negativo. Durante o período de análise foram realizadas 526 Intervenções à Vista.

c) Títulos Cambiais

Além de intervir no mercado à vista, o Banco Central pode intervir nas dinâmicas da taxa de câmbio vendendo títulos cambiais. Desconsiderando o risco de default, os títulos indexados pela taxa de câmbio são substitutos na oferta de moeda sob a perspectiva que demandam hedge de câmbio. Então, a emissão 
Figure 3: Mercado à vista

Período A

Período C

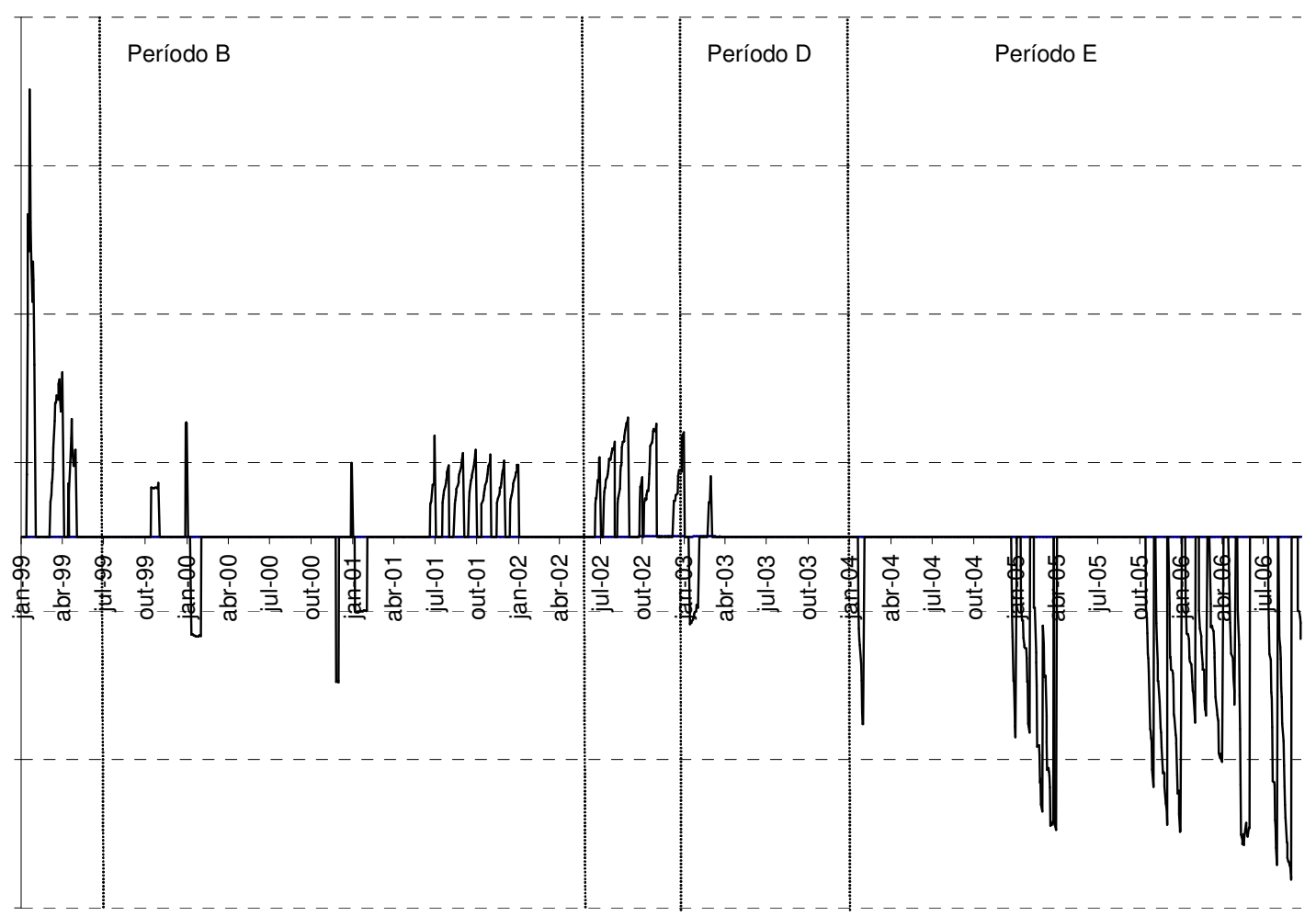

destes títulos é uma maneira alternativa de intervir no mercado de câmbio. Os principais títulos de dívida destas operações foram a NBC-E e a NTN-D, aonde suas remunerações são atreladas a uma taxa de juros fixa mais a variação cambial. O primeiro título é de responsabilidade do Banco Central enquanto que o segundo é de responsabilidade do Tesouro Nacional. Ao recomprar (ou emitir) títulos cambiais aos agentes domésticos, o Banco Central (ou Tesouro Nacional) está aumentando (ou reduzindo) a exposição do mercado à moeda nacional em seus portfólios.

A série de títulos cambiais foi obtida junto ao Departamento de Mercado Aberto do Banco Central e como houve uma alteração na metodologia de apreçamento dos títulos, foram criadas duas séries de dados. A primeira apresentava bases diárias até outubro de 2002 e utilizava-se o preço de lastro dos títulos. A segunda a partir de outubro/2002, os títulos passaram a ser precificados a partir da curva do papel.

Para obtenção das intervenções por meio de títulos cambiais, utilizamos o seguinte procedimento:

(i) obtivemos o volume do estoque de títulos em poder do mercado em dólares americanos;

(ii) apuramos a variação nominal dia a dia desta base;

(iii) com isso obtivemos uma série com o volume de operações diárias de títulos cambias; 
Figure 4: Títulos cambiais

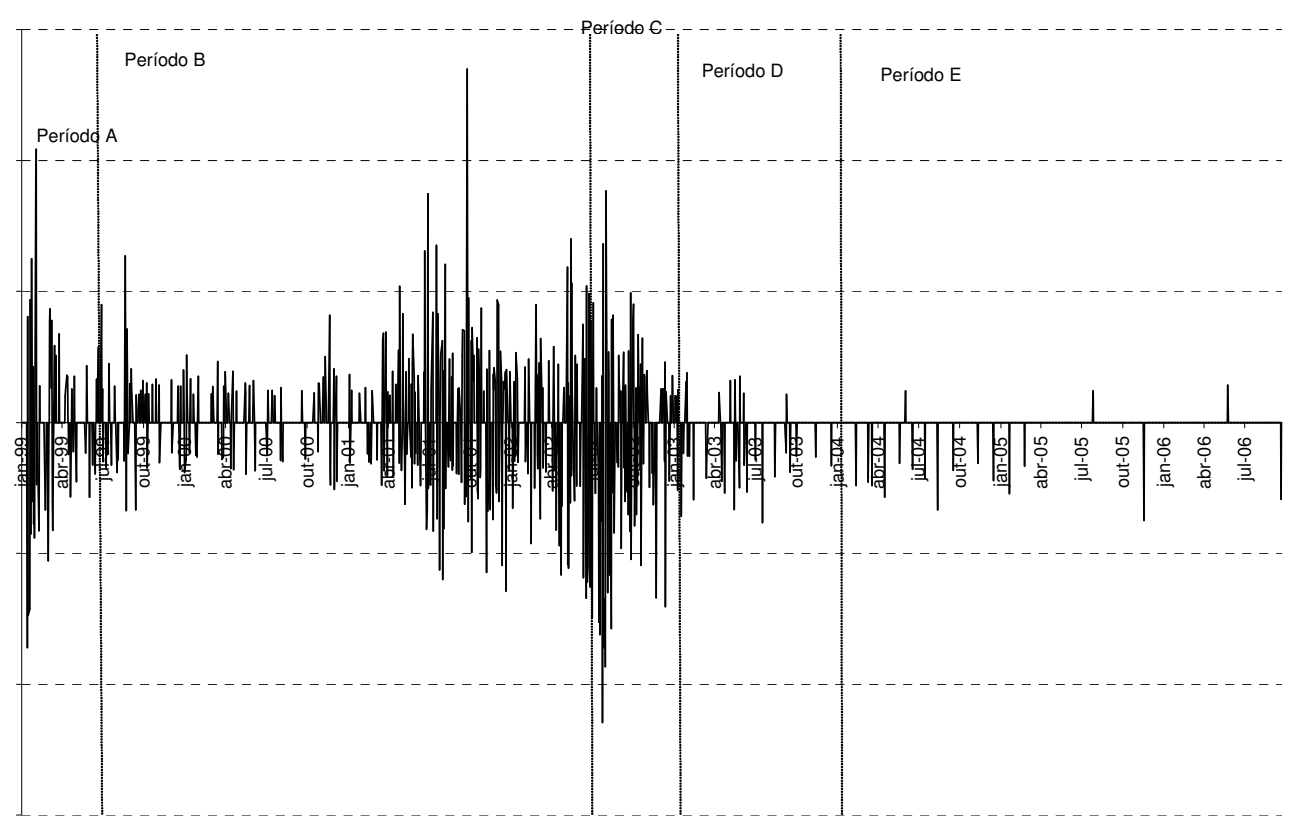

(iv) esta série foi separada em duas: uma com as operações de compra e outra com as operações de venda;

(v) calculamos o desvio padrão para cada uma destas séries;

(vi) definimos que intervenções seriam aquelas operações que tivessem módulo superior a média mais um desvio padrão.

A utilização dos instrumentos de títulos cambiais foi bastante intensa durante as fases de crises cambiais até 2003, quando a emissão de novos títulos foi interrompida. A partir desta data, as intervenções consistiram basicamente em redução do estoque em poder do mercado. Pelo Teste de Raiz Unitária, percebemos que esta tendência é determinística (valor crítico pelo teste Elliott-RothenbergStock DF-GLS igual a -6.25), logo não foram necessárias transformações.

d) Swaps Cambiais

O Banco Central também pode intervir por meio de contratos de swaps de câmbio. A lei de Responsabilidade Fiscal tornou ilegal a emissão de títulos emitidos pelo Banco Central, o que fez com que ele procurasse instrumentos alternativos para implementar sua política de câmbio. A partir de abril de 2002 o Banco Central começou a vender LFT que é um título com juros fixos, junto com swaps de câmbio. Nestas trocas ele ficava short na depreciação da taxa de câmbio nominal e long na taxa de juros flutuante, DI. A combinação de LFT e swaps eram equivalente a títulos cambiais.

Os contratos de swaps cambiais registrados no Brasil como clearings de derivativos na BMF. Consideramos os swaps de câmbio no período de abril de 2002 a setembro de 2006. De acordo com o Banco Central, uma vantagem desta nova modalidade é que ao trocar os títulos cambiais por LFTs, o passivo 
Table 5: Intervenções via Títulos Cambiais

\begin{tabular}{ccccccc}
\hline Tipo de Intervenções & $\begin{array}{c}\text { Período (A) } \\
\text { 01/01/99 }\end{array}$ & $\begin{array}{c}\text { Período (B) } \\
31 / 05 / 02\end{array}$ & $\begin{array}{c}\text { Período (C) } \\
01 / 07 / 99\end{array}$ & $\begin{array}{c}\text { Período (D) } \\
01 / 03 / 03\end{array}$ & $\begin{array}{c}\text { Período (E) } \\
01 / 01 / 04\end{array}$ & $\begin{array}{c}\text { TOTAL } \\
01 / 01 / 99\end{array}$ \\
& $30 / 06 / 99$ & $31 / 12 / 02$ & $30 / 05 / 02$ & $31 / 12 / 03$ & $21 / 09 / 06$ & $21 / 09 / 06$ \\
\hline Títulos Cambiais & 52 & 94 & 284 & 35 & 18 & 483 \\
Compra & 26 & 50 & 132 & 24 & 15 & 247 \\
Venda & 26 & 44 & 152 & 11 & 3 & 236 \\
\hline
\end{tabular}

A Tabela 5 resume a frequência de Intervenções via Títulos Cambiais ao longo do horizonte de estimação correspondente a janeiro de 1999 a setembro de 2006. Os dados são diários. Os instrumentos foram separados em operações de compra e venda. Por convenção definimos que as vendas de dólares possuem sinal positivo, enquanto as compras de dólares possuem sinal negativo. Durante o período de análise foram realizadas 483 Intervenções via Títulos Cambiais.

do principal da dívida passa a ser contabilizado no balanço do Tesouro Nacional, enquanto o passivo cambial entra na contabilidade do Banco Central, reduzindo desta forma a carga sobre o balanço do Bacen. Com isso, o requerimento de margens e spreads também é reduzido, o que minimiza o custo total da operação de proteção aos agentes de mercado, tendo em vista que a nova sistemática permite que o mercado negocie separadamente os dois instrumentos.

De acordo com o Departamento de Operações do Mercado Aberto - DEMAB, no ano de 2002, foi realizado um número inédito de leilões de compra e de troca de títulos públicos e de swap cambial, visando conter a volatilidade do preço dos títulos e reduzir a pressão sobre a taxa de câmbio. Entre março e novembro de 2002 , foram realizados em torno de 200 leilões.

O procedimento de obtenção da série de intervenções via swaps foi idêntico ao utilizado para o caso de títulos. Pelo Teste de Raiz Unitária, percebemos que esta tendência é determinística ao nível de 10\% (valor crítico pelo teste Elliott-Rothenberg-Stock DF-GLS igual a -2.81), logo não foram necessárias transformações na variável.

Table 6: Intervenções via Títulos Cambiais

\begin{tabular}{ccccccc}
\hline Tipo de Intervenções & $\begin{array}{c}\text { Período (A) } \\
\text { 01/01/99 }\end{array}$ & $\begin{array}{c}\text { Período (B) } \\
31 / 05 / 02\end{array}$ & $\begin{array}{c}\text { Período (C) } \\
01 / 07 / 99\end{array}$ & $\begin{array}{c}\text { Período (D) } \\
01 / 03 / 03\end{array}$ & $\begin{array}{c}\text { Período (E) } \\
01 / 01 / 04\end{array}$ & $\begin{array}{c}\text { TOTAL } \\
01 / 01 / 99\end{array}$ \\
& $30 / 06 / 99$ & $31 / 12 / 02$ & $30 / 05 / 02$ & $31 / 12 / 03$ & $21 / 09 / 06$ & $21 / 09 / 06$ \\
\hline Swaps & 0 & 37 & 3 & 41 & 84 & 165 \\
Compra & 0 & 14 & 0 & 23 & 84 & 121 \\
Venda & 0 & 23 & 3 & 18 & 0 & 44 \\
\hline
\end{tabular}

A Tabela 6 resume a frequência de Intervenções via Swaps Cambiais ao longo do horizonte de estimação correspondente a janeiro de 1999 a setembro de 2006. Os dados são diários. Os instrumentos foram separados em operações de compra e venda. Por convenção definimos que as vendas de dólares possuem sinal positivo, enquanto as compras de dólares possuem sinal negativo. Durante o período de análise foram realizadas 165 Intervenções via Swaps Cambiais.

\section{O MODELO DA VOLATILIDADE CONDICIONAL DA TAXA DE CÂMBIO NOMINAL}

Em modelos econométricos convencionais, a variância do erro é considerada constante. Analisando o gráfico da variação diária do logaritmo da taxa de câmbio nominal (Figura 1), percebemos que existem 
Figure 5: Swaps cambiais

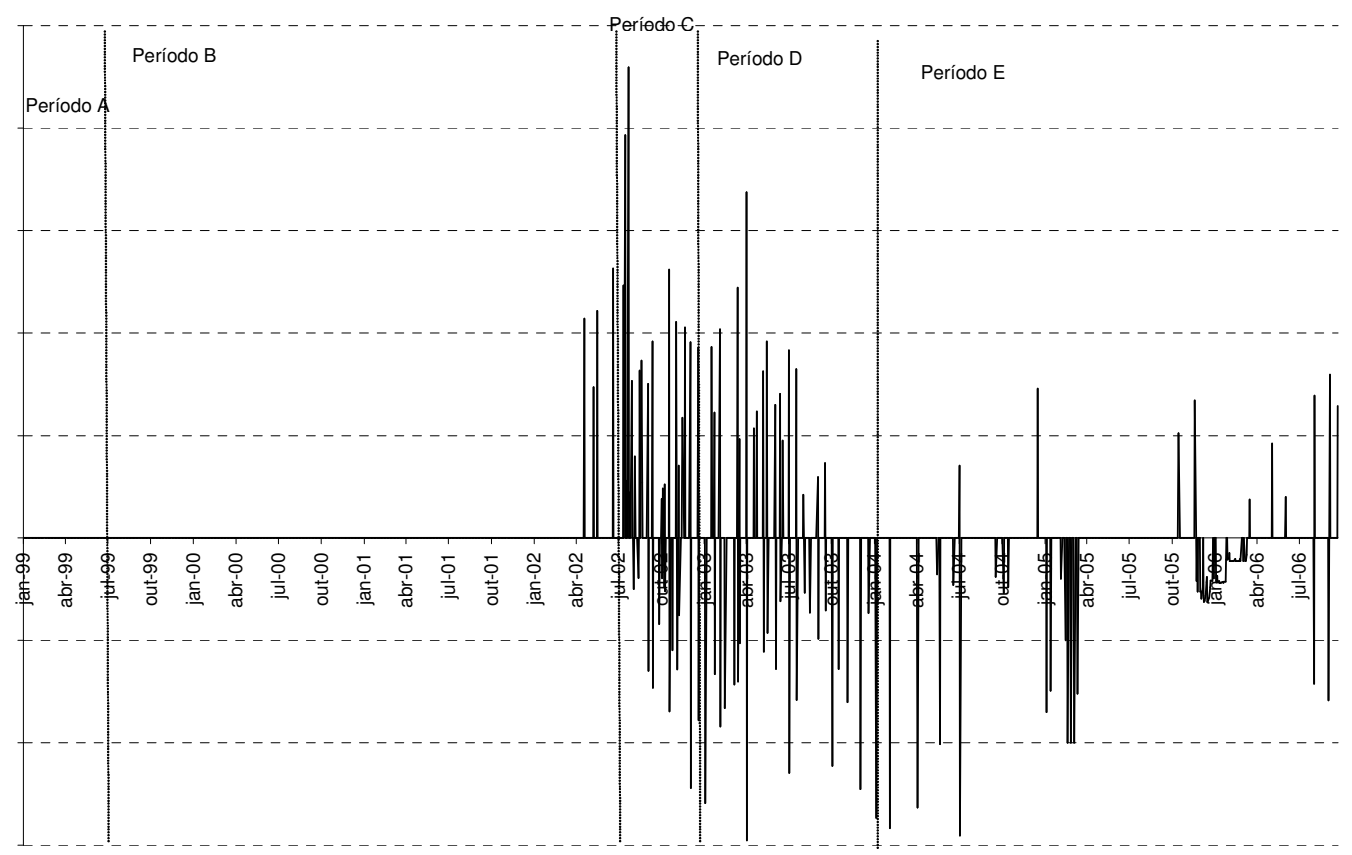

períodos com pequenas variações da série, acompanhados de períodos de elevações e quedas acentuadas da taxa de câmbio (períodos de crise cambial). Essas características sugerem a heterocedasticidade condicional. Assim, precisamos utilizar um modelo que estime a média e a variância de uma da série de forma simultânea, para quando a variância do erro não for constante.

O modelo GARCH (Generalized Autoregressive Conditional Heteroskedastic) de Bollerslev (1986) seria o candidato natural para este tipo de análise. Mas este modelo impõe uma condição de não-negatividade para garantir que a variância condicional do erro seja maior que zero. Para solucionarmos este problema poderíamos "seguir os passos" de Dominguez (1993), que na tentativa de evitar a violação desta condição, considerou os valores das compras e vendas das intervenções do Banco Central em valores absolutos. Mas segundo Nelson e CAo (1992), coeficientes positivos dão uma condição suficiente, mas não necessária para que a variância condicional seja positiva. Essa transformação também não permite a análise e distinção dos efeitos positivos e negativos na variância condicional (assimetria da distribuição) comum em variáveis econômicas. Ela foca apenas no impacto total da intervenção na volatilidade condicional da taxa de câmbio nominal. Adicionalmente, Beine et alii (2006) encontraram evidências de que o modelo GARCH tende a subestimar os efeitos das intervenções do Banco Central na volatilidade da taxa de câmbio nominal.

Alguns artigos utilizaram o modelo E-GARCH (Exponential GARCH) de Nelson e CAo (1992) para analisar o impacto das intervenções realizadas pelo Banco Central na volatilidade condicional. Destacamos os trabalhos de Domaç e Mendonza (2002) que utilizaram o modelo E-GARCH para analisar o impacto das intervenções realizadas pelo Banco Central do México e da Turquia na volatilidade da taxa de câmbio nominal. Kim et alii (1998) analisaram a eficácia das intervenções do Banco Central da Austrália na volatilidade condicional durante o período de 1983-1997 utilizando o modelo E-GARCH. Araújo e 
Goldfajn (2004) investigaram os efeitos das intervenções do Banco Central no mercado brasileiro nos períodos de 2000 a 2003 por meio do modelo E-GARCH.

Estes estudos empíricos escolheram o modelo E-GARCH baseado nas suas características econométricas: permite assimetria de choques na volatilidade e não impõe restrições de não-negatividade da variância. Neste modelo, também podemos expressar de forma mais parcimoniosa a dependência temporal da variância condicional, descrevendo a volatilidade condicional com menos parâmetros que no modelo ARCH de Engle (1982).

Baseado nestes argumentos este estudo utilizou o modelo E-GARCH, pois queremos analisar tanto o efeito total das intervenções realizadas pelo Banco Central, assim como, o efeito individual dos instrumentos de intervenção, tanto para operações de compra, como para operações de venda. Queremos capturar também, o impacto de intervenções altistas (compra de divisas contra a moeda local) e baixistas (vendas de divisas contra a moeda local) na volatilidade condicional da taxa de câmbio nominal.

O modelo E-GARCH é estimado usando o procedimento de conditional maximum likelihood. Os parâmetros estimados são obtidos por meio de métodos numéricos de maximização da variância condicional. Este modelo deverá capturar toda a dinâmica da média e da variância condicional. Os resíduos estimados são serialmente não correlacionados e não devem apresentar vestígio de variância condicional, caso contrário, o modelo não estaria corretamente especificado.

Iremos denotar as operações de intervenção como $I_{t}$. A interpretação para a variável de intervenção é: se o valor de $I_{t}$ for positivo, significa que o Banco Central está injetando dólares na economia e o real irá apreciar relativamente ao dólar, caso contrário, se o Banco Central adotar políticas contracionistas, isto é, valores negativos de $I_{t}$, o real irá depreciar relativamente ao dólar.

O modelo empírico das mudanças no câmbio pode ser expresso por:

$$
\triangle s_{t}=b_{0}+b_{1} \triangle s_{t-1}+b_{2} \triangle i_{t}+b_{3} I_{t}^{V I S T}+b_{4} I_{t}^{T I T U}+b_{5} I_{t}^{S w a p}+e_{t}
$$

onde:

$\triangle s_{t}=$ variação do logaritmo natural da taxa de câmbio corrente (R\$ /US\$);

$\triangle i_{t}=$ taxa de juros doméstica ou taxa Selic;

$I_{t}^{V I S T}=$ intervenções à vista;

$I_{t}^{T I T U}=$ intervenções via títulos públicos (NTN-D e NBC-E);

$I_{t}^{S w a p}=$ intervenções via LFT com swap cambial;

$e_{t}=$ termo de distúrbio.

$$
E\left[\epsilon_{t}\right]=0 ; \operatorname{Var}\left[\epsilon_{t}\right]=\sigma_{t}^{2} ; E\left[\epsilon_{t} \epsilon_{t-s}\right]=0 ; \epsilon_{t}=e_{t} h_{t} \quad \text { e } \quad e_{t} \sim N(0,1)
$$

Se a intervenção feita pelo Banco Central não sinalizar mudança nos fundamentos, mas sim nos movimentos de curto prazo da taxa de câmbio, assim $E\left[\epsilon_{t} \mid I_{t-1}\right] \neq 0$ e $I_{t-1}$ não será uma variável apropriada.

A média condicional de $\epsilon_{t}$ é igual a zero e sua variância condicional $\left(h_{t}\right)$ no modelo E-GARCH é igual a:

$$
\ln h_{t}=\alpha_{0}+\alpha_{1} \frac{\epsilon_{t-1}^{2}}{h_{t-1}^{0.5}}+\lambda_{1}\left|\frac{\epsilon_{t-1}}{h^{0.5} t-1}\right|+\alpha_{2} \triangle i_{t}+\alpha_{3} I_{t}^{V I S T}+\alpha_{4} I_{t}^{T I T U}+\alpha_{5} I_{t}^{S w a p}+\beta_{1} \ln h_{t-1}+v_{t}
$$

onde $v_{t}$ é ruído branco. 
No modelo E-GARCH os valores de $\epsilon_{t-1}^{2}$ são padronizados por $H_{t-1}^{0.5}$ o que nos permitirá a interpretação do tamanho ( $\alpha_{1}$ e $\lambda_{1}$ ) e da persistência dos choques $\left(\beta_{1}\right)$. Se $\frac{\epsilon_{t-1}^{2}}{h_{t-1}^{0.5}}$ for positivo o efeito de influência dos choques na variância condicional será igual a $\alpha_{1}+\lambda_{1}$. Caso contrário, o efeito de influência dos choques será igual a $-\alpha_{1}+\lambda_{1}$.

O termo $\beta_{1}$ irá captar a persistência da variância condicional ao longo do tempo. Se $\beta_{1}$ for significantemente maior que zero, uma desvalorização do real frente ao dólar contribuirá para uma maior variância condicional.

Iremos assumir como instrumento de intervenção $\left(I_{t}\right)$ em nosso modelo as taxa de juros domésticos (taxa Selic), as compras e vendas de dólares no mercado à vista, os títulos públicos atrelados ao dólar ((NTN-D e NBC-E) e os swaps cambias (LFT com swap cambial).

Nosso objetivo é capturar o comportamento da volatilidade da taxa de câmbio nominal por meio das intervenções cambiais feitas pelo Banco Central. Iremos testar duas hipóteses: a primeira hipótese é se as intervenções impactam a volatilidade cambial. Caso positivo, os coeficientes $\alpha_{2}, \alpha_{3}, \alpha_{4}$ e $\alpha_{5}$ precisam ser significantemente diferente de zero. A segunda hipótese a ser testada é se as intervenções conseguem diminuir a volatilidade da taxa de câmbio nominal, com intuito de transformar a relação real-dólar mais estável, especialmente em momentos de crise. Para isso os coeficientes $\alpha_{2}, \alpha_{3}, \alpha_{4}$ e $\alpha_{5}$ precisam ser significativos e ter sinais negativos. Como a equação da média possui pouco interesse em nossa análise, dado que a taxa de câmbio tem um comportamento de passeio aleatório, iremos apresentar somente os valores estimados para a equação da variância.

Iremos supor que, as intervenções são exógenas à variação da taxa de câmbio nominal, o que nos permitirá uma interpretação consistente dos coeficientes estimados e nos permite ignorar problemas de endogeneidade na estimação dos parâmetros.

\section{ANÁLISE EMPÍRICA}

\subsection{Modelo E. GARCH}

Neste capítulo iremos apresentar os resultados dos parâmetros estimados pelo modelo E-GARCH $(1,1)$ no período de janeiro/99 a setembro/2006.

Antes de estimar o modelo de volatilidade condicional da taxa de câmbio nominal, fizemos o correlograma do quadrado dos resíduos com 36 defasagens e percebemos que ele possui a ordem $(1,1)$. Utilizamos o método de Bollerv e Wooldridge para gerar uma matriz de covariância consistente, ainda que a distribuição dos erros não seja normal. O algoritmo de otimização utilizado foi o de Marquardt. Os valores estimados estão reportados na Tabela 7 e os $p$-valores estão entre parêntesis.

Vamos começar analisando as intervenções nos períodos de crises cambiais. Analisando a equação da variância para os períodos com crise (Período A e C), percebemos que para o Período A (janeiro/1999 a junho/1999), o único instrumento de intervenção eficaz em afetar a volatilidade condicional da taxa de câmbio em momentos de crise foi intervenção à vista, cujo valor foi significativo ao nível de $10 \%$. $\mathrm{O}$ coeficiente das intervenções à vista é positivo e de pequeno valor (igual a 0.000245 ), indicando um aumento na variância condicional.

Este resultado é um tanto curioso, visto que ao intervir em momentos de crise, esperamos que o Banco Central consiga reduzir a volatilidade condicional da taxa de câmbio nominal. Uma possível explicação para este fato talvez seja a magnitude da crise cambial acontecida neste período. $\mathrm{O}$ abandono do regime de câmbio fixo provocou fugas em massa de capitais do Brasil, assim como gerou tal incerteza dos investidores internacionais sobre a economia brasileira que impossibilitou que o Banco Central do Brasil diminuísse a excessiva volatilidade do mercado cambial. Além disso, o país não possuía na época volume de reservas internacionais suficientes para fazer frente ao ataque especulativo.

Para o Período C (maio/2002 a dezembro/2002), o único instrumento de intervenção que afetou a volatilidade da taxa de câmbio nominal foi à intervenção via títulos cambiais, cujo valor foi significativo 
ao nível de $10 \%$. Seu coeficiente é negativo (igual a -0.000165), indicando uma redução da variância condicional da taxa de câmbio nominal. Os demais instrumentos de intervenção não são significativos para ambos os períodos ao nível de $10 \%$.

O que pode ter ajudado o Banco Central a reduzir a volatilidade com este instrumento foi o fato do volume de títulos ofertados pelo Banco Central ter sido substancial entre 1999 e 2002, sinalizando claramente a intenção de conter 0 ataque especulativo sem drenar suas reservas internacionais ou aumentar a taxa de juros, que traria prejuízo para o crescimento do país podendo gerar ainda mais incerteza nos investidores internacionais.

Outra possível explicação para o fato dos títulos cambiais terem sido eficazes para reduzir a volatilidade cambial está ligada à demanda por hedge cambial no Brasil. Como mostra Oliveira (2004), um grande número de firmas do setor real da economia possuía contratos de swaps cambiais com o mercado financeiro. As firmas em geral estavam na contraparte comprada em dólar enquanto as instituições financeiras estavam na contraparte vendida. Para reduzir o risco dessas transações, as instituições financeiras buscavam no Banco Central do Brasil derivativos cambiais em que estivessem também comprados em dólares. Títulos cambiais e swaps cambiais foram estes instrumentos. Cremos que os swaps não foram eficazes por conta do fato de ser um mercado novo naquele momento, com volume de negociação inferior ao mercado de títulos cambiais.

Há diversas maneiras de intervenções esterilizadas do Banco Central afetar a volatilidade da taxa de câmbio nominal, como explicam Sarno e Taylor (2001). Uma explicação possível e que cremos ser a melhor para explicar nossos resultados acima está relacionada ao efeito sinalizador. Nesta explicação, a intervenção serve como uma informação sobre a política monetária futura. Ela pode alterar as expectativas do mercado sobre a taxa de câmbio futura e indicar para onde o banco central deseja que ela se movimente. $^{12}$

Vamos agora analisar a eficácia dos instrumentos nos períodos sem crise cambial. Analisando a equação da variância, vide Tabela 7, para os períodos sem crise (Períodos B, D e E), percebemos que a eficácia dos instrumentos variou dependendo do período de análise. No Período B (julho/1999 a maio/2002), o único instrumento de intervenção não significativo ao nível de $5 \%$ foi à intervenção via Swaps cambiais. A taxa de juros Selic, as intervenções via títulos cambiais e intervenções à vista foram significativas ao nível de $5 \%$. Todos os instrumentos de intervenção adicionaram volatilidade à taxa de câmbio nominal visto que seus coeficientes são positivos e significativos.

No Período D (março/2003 a dezembro/2003), nenhum instrumento de intervenção afetou de forma significativa a volatilidade cambial. Rejeitamos a hipótese de assimetria dos choques para este período, mas não rejeitamos a existência de resistência auto-regressiva condicional e a persistência dos choques, ambos são significativos ao nível de $1 \%$ e $10 \%$ respectivamente.

No Período E (janeiro/2004 a setembro/2006), o único instrumento de intervenção significativo foi a taxa de juros Selic, significativa ao nível de $10 \%$, que contribuiu para uma redução da volatilidade cambial (coeficiente igual a -60.08).

Assim, concluímos que a eficácia dos instrumentos de intervenção variou, dependendo da existência ou não de crises cambiais e do período analisando. Para o primeiro período de elevada volatilidade cambial, compreendido entre janeiro de 1999 e junho de 1999, o Banco Central não foi eficaz em transformar a relação real-dólar mais estável. O único instrumento de intervenção significativo utilizado pela Autoridade Monetária foi à intervenção no mercado à vista, que adicionou volatilidade a taxa de câmbio nominal. Para o segundo período de crise cambial (maio de 2002 a dezembro de 2002), o Banco Central conseguiu reduzir a volatilidade cambial através de títulos cambiais.

\footnotetext{
${ }^{12}$ Há duas outras teorias conhecidas como canal de portfólio e canal de coordenação. A primeira se baseia na substituição imperfeita entre ativos domésticos e externos. Com a crescente integração entre os mercados internacionais de capitais e aumento da substituição entre ativos, esta explicação tem perdido importância recentemente. A segunda está relacionada a interevnções coordenadas de países do G7, em particular EUA e Japão. A teoria da sinalização parece mais adequada para explicar os efeitos das intervenções cambiais do Banco Central no caso brasileiro.
} 
O curioso é que a taxa de juros Selic não conseguiu acalmar o mercado de câmbio em momento de crise. Uma possível explicação para tal resultado, é que este instrumento de intervenção é utilizado para alterar a dinâmica da taxa de inflação e não para afetar a taxa de câmbio nominal, visto a implementação do sistema de metas de inflação no Brasil, a partir de janeiro de 1999.

Cremos que o Banco Central tenha após a crise cambial de 1999, implementado diversas políticas macroeconômicas - como sistema de metas de inflação, regime de câmbio flutuante entre outras que aumentaram sua credibilidade junto ao mercado. Isto permitiu a ele sinalizar melhor, por meio de intervenções no mercado cambial, sua futura política monetária. Como consequência, aumentando a eficácia dos instrumentos de intervenção cambial.

Figure 6: Estimativa da volatilidade dada pelo modelo de volatilidade cambial

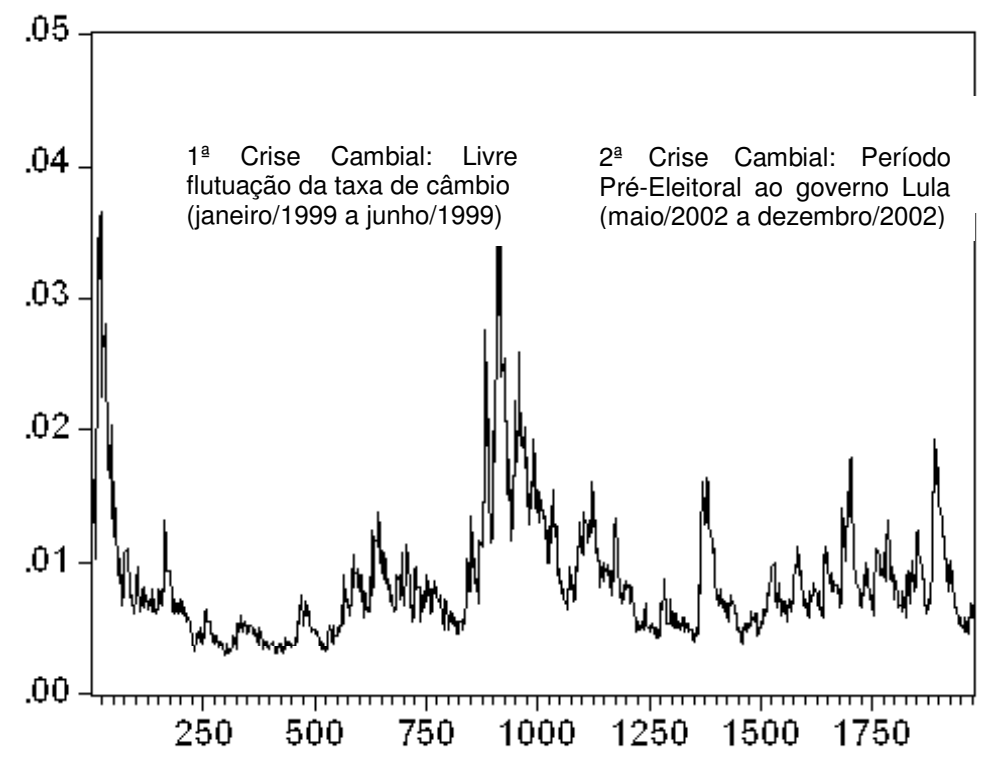

Tempo

\subsection{Análise de Robustez}

Não há ainda um consenso ainda na literatura sobre o melhor modelo para a taxa de câmbio nominal. Diversos autores, como Domingues (1998) modelam-na como um processo ARCH. No Brasil, há autores, Souza et al (2006) que modelam a taxa de câmbio nominal como um processo de memória longa na classe dos modelos FIGARCH. Portanto, vamos começar testando a robustez dos resultados acima, alterando a especificação dos modelos estimados até aqui. Iremos estimar um modelo GARCH como nas equações (4) e (5) e um modelo IGARCH (um caso particular de um modelo FIGARCH) como nas equações (6) e (7).

$$
\triangle s_{t}=b_{0}+b_{1} \triangle s_{t-1}+b_{2} \triangle i_{t}+b_{3} I_{t}^{V I S T}+b_{4} I_{t}^{T I T U}+b_{5} I_{t}^{S W A P}+e_{t}
$$


Table 7: Intervenções do Banco Central e a Volatilidade Condicional da Taxa de Câmbio Nominal: Períodos com Crise Cambial e sem Crise Cambial

\begin{tabular}{lccccc}
\hline & \multicolumn{2}{c}{ Com crises cambiais } & \multicolumn{3}{c}{ Sem crises cambiais } \\
\hline \multirow{2}{*}{ Período } & $(\mathrm{A})$ & $(\mathrm{C})$ & $(\mathrm{B})$ & $(\mathrm{D})$ & $(\mathrm{E})$ \\
& $01 / 01 / 99$ & $31 / 05 / 02$ & $01 / 07 / 99$ & $01 / 01 / 03$ & $01 / 01 / 04$ \\
& $30 / 06 / 99$ & $31 / 12 / 02$ & $30 / 05 / 02$ & $31 / 12 / 03$ & $21 / 09 / 06$ \\
\hline Variável & Eq. var. & Eq. var. & Eq. var. & Eq. var. & Eq. var. \\
independente & & & & & \\
\hline Constante & $-6,035751$ & $-0,839257$ & $-0,55041$ & $-2,58506$ & $-1,188847$ \\
& $(0,0382)$ & $(0,0801)$ & $(0,0001)$ & $(0,0904)$ & $(0,0043)$ \\
Coef. persistência da & 0,380693 & 0,923584 & 0,961473 & 0,776113 & 0,899700 \\
Variância condicional & $(0,1912)$ & $(0,0000)$ & $(0,0000)$ & $(0,0000)$ & $(0,0000)$ \\
Coef. persistência & $-0,159455$ & 0,230827 & 0,183186 & 0,226201 & 0,242845 \\
dos choques & $(0,6000)$ & $(0,0112)$ & $(0,0000)$ & $(0,0726)$ & $(0,0002)$ \\
Coef. assimetria & $-0,209558$ & 0,097883 & 0,027719 & $-0,08500$ & 0,113456 \\
dos Choques & $(0,1642)$ & $(0,2198)$ & $(0,1333)$ & $(0,3105)$ & $(0,0518)$ \\
Retorno da & $-59,28922$ & 3,592054 & 23,20830 & $-167,734$ & $-60,07819$ \\
Taxa Selic & $(0,3114)$ & $(0,9187)$ & $(0,0048)$ & $(0,1853)$ & $(0,0888)$ \\
Swap & & $-2,38 \mathrm{E}-05$ & 0,000280 & 0,000151 & $-6,26 \mathrm{E}-05$ \\
& - & $(0,8323)$ & $(0,1575)$ & $(0,4080)$ & $(0,5431)$ \\
Título cambial & $9,70 \mathrm{E}-05$ & $-0,000165$ & 0,000108 & $-0,00012$ & $-0,000293$ \\
& $(0,4112)$ & $(0,0061)$ & $(0,0155)$ & $(0,6945)$ & $(0,1942)$ \\
Mercado à vista & 0,000245 & $2,75 \mathrm{E}-05$ & $5,99 \mathrm{E}-05$ & $-0,00021$ & $4,93 \mathrm{E}-07$ \\
& $(0,0891)$ & $(0,5406)$ & $(0,0105)$ & $(0,1822)$ & $(0,9788)$ \\
$\mathrm{R}^{2}$ & 0,826464 & 0,222934 & 0,398428 & 0,090279 & 0,006142 \\
\hline
\end{tabular}

O horizonte da estimação compreende o período de janeiro de 1999 a setembro de 2006. Os dados são diários. Os períodos estimados são os períodos de crise cambiais (janeiro de 1999 a junho de 1999 e julho de 1999 a maio de 2002), os períodos estimados sem crise cambial (maio de 2002 a dezembro de 2002, março de 2003 a dezembro de 2003 e janeiro de 2004 a setembro de 2006) e todo o período. A variável dependente é a Volatilidade Condicional da Taxa de Câmbio Nominal. Estamos estimando o conjunto de parâmetros: Coeficiente de Persistência da Variância Condicional, Coeficiente de Persistência dos Choques na Variância Condicional, Coeficiente de Assimetria dos Choques na Variância Condicional, a variação da taxa de juros Selic, Intervenções à Vista, Intervenções via Títulos Cambiais e Intervenções via Swaps Cambias. Em parêntesis estão informados os $p$-valores. Durante o período de análise foram realizadas 1.174 intervenções. Deste total 526 foram Intervenções à Vista, 483 foram Intervenções Títulos Cambiais e 165 foram Intervenções via Swaps Cambiais. 


$$
\begin{gathered}
h_{t}=\alpha_{0}+\alpha_{1} \epsilon_{t-1}^{2}+\alpha_{5} \triangle i_{t}+\alpha_{6}\left|\left(I_{t}^{V I S T}\right)\right|+\alpha_{7}\left|\left(I_{t}^{T I T U}\right)\right|+\alpha_{8}\left|I_{t}^{S W A P}\right|+\beta_{1} h_{t-1}+v_{t} \\
\triangle s_{t}=b_{0}+b_{1} \triangle s_{t-1}+b_{2} \triangle i_{t}+b_{3} I_{t}^{V I S T}+b_{4} I_{t}^{T I T U}+b_{5} I_{t}^{S W A P}+e_{t}
\end{gathered}
$$

$h_{t}+\alpha_{0}+\alpha_{1} \epsilon_{t-1}^{2}+\alpha_{5} \triangle i_{t}+\alpha_{6}\left|\left(I_{t}^{V I S T}\right)\right|+\alpha_{7}\left|\left(I_{t}^{T I T U}\right)\right|+\alpha_{8}\left|I_{t}^{S W A P}\right| \beta_{1} h_{t-1}+v_{t}$, onde $\alpha_{1}+\beta_{1}=1$

onde as intervenções $I_{t}^{V I S T}, I_{t}^{T I T U}$ e $I_{t}^{S W A P}$ estão agora em módulo. Os valores estimados estão reportados na Tabela 8 e os $p$-valores estão entre parêntesis.

A Tabela 8 Painel A apresenta os resultados para o modelo GARCH. Podemos ver que os resultados são muito semelhantes aos encontrados com o modelo EGARCH. Isto se repete também para o modelo IGARCH estimado cujos resultados estão na Tabela 8 Painel B. Vemos mais uma vez que o único instrumento de intervenção que conseguiu diminuir a volatilidade condicional da taxa de câmbio nas crises cambiais foi à intervenção via Título Cambial, na segunda crise cambial. Mais uma vez, as intervenções no mercado à vista adicionaram volatilidade na primeira crise cambial. Fora dos períodos de crise cambial, um ou outro instrumento afetou também a volatilidade condicional da taxa de câmbio tal qual no modelo E.GARCH estimado anteriormente.

Como uma segunda tentativa de testar a robustez dos nossos resultados, iremos re-estimar o modelo (2) e (3), somando as intervenções via Swaps e Títulos Cambiais. O motivo pelo qual iremos considerar esses dois instrumentos de intervenção como uma única variável explicativa, se deve à correlação destas duas variáveis, visto que são substitutos muito próximo um do outro. A correlação entre a série dos títulos cambiais e a série dos swaps cambiais no período de abril de 2002 a abril de 2003 foi igual a -0,87. Os valores estimados estão reportados na Tabela 8 e os $p$-valores estão entre parêntesis. Consideramos como intervenção do Banco Central aquelas com valor superior em módulo à média mais um desvio padrão. Com este critério, identificamos 615 intervenções no período de janeiro de 1999 a setembro de 2006.

Analisando os resultados da Tabela 9, verificamos que o instrumento de intervenção que é a soma de títulos públicos com swaps cambiais reduziu a volatilidade condicional da taxa de câmbio nominal na segunda crise cambial. Nos outros períodos sem crise cambial, além deste instrumento as intervenções no mercado à vista também foram eficazes.

Em uma terceira tentativa, para testar a robustez dos nossos resultados separamos as operações de compra e venda dos instrumentos de intervenção para investigar se intervenções positivas e negativas afetam a volatilidade condicional da taxa de câmbio. Por questões de espaço, não reportamos os resultados, mas eles confirmam que o único instrumento de intervenção que conseguiu diminuir a volatilidade condicional da taxa de câmbio foi às intervenções por meio de compra de títulos cambiais durante a segunda crise cambial. Mais uma vez, intervenções à vista acrescentaram volatilidade condicional na primeira crise cambial e nos períodos sem crise um ou outro instrumento foi eficaz.

Finalmente, separamos as operações de compra e venda dos instrumentos de intervenção e somamos os instrumentos de intervenção via Swaps e Títulos Cambiais. Não reportamos o resultado por questões de espaço, mas uma vez mais eles estão em acordo com os resultados da análise empírica principal apresentada na Seção 4 acima.

Em síntese, nossas análises de robustez confirmam nossos resultados prévios. Nas crises cambiais, o único instrumento eficaz para reduzir a volatilidade foram as intervenções por meio de títulos cambiais. Fora das crises cambiais, o Banco Central do Brasil foi eficaz para afetar a volatilidade condicional da taxa de câmbio com um ou outro instrumento de intervenção. 
Table 8: Intervenções com Modelos GARCH e FIGARCH da Taxa de Câmbio Nominal

\begin{tabular}{|c|c|c|c|c|c|}
\hline \multicolumn{6}{|l|}{ Painel A } \\
\hline \multicolumn{6}{|c|}{ Variável Dependente: Volatilidade Condicional da Taxa de Câmbio Nominal } \\
\hline & \multicolumn{2}{|c|}{ Com crises cambiais } & \multicolumn{3}{|c|}{ Sem crises cambiais } \\
\hline & (A) & (C) & (B) & (D) & $(\mathrm{E})$ \\
\hline Período & $01 / 01 / 99$ & $31 / 05 / 02$ & $01 / 07 / 99$ & $01 / 01 / 03$ & $01 / 01 / 04$ \\
\hline & $30 / 06 / 99$ & $31 / 12 / 02$ & $30 / 05 / 02$ & $31 / 12 / 03$ & $21 / 09 / 06$ \\
\hline $\begin{array}{l}\text { Variável } \\
\text { independente }\end{array}$ & Eq. var. & Eq. var. & Eq. var. & Eq. var. & Eq. var. \\
\hline Constante & $\begin{array}{c}0,000014 \\
(0,16)\end{array}$ & $\begin{array}{c}0,000065 \\
(0,26)\end{array}$ & $\begin{array}{c}4,2 \mathrm{E}-05 \\
(0,50)\end{array}$ & $\begin{array}{c}2,52 \mathrm{E}-6 \\
(0,31)\end{array}$ & $\begin{array}{c}1,19 \mathrm{E}-6 \\
(0,50)\end{array}$ \\
\hline Coef. Persistência da & 0,17 & 0,83 & 0,53 & 0,67 & 0,74 \\
\hline Variância Condicional & $(0,54)$ & $(0,0)$ & $(0,05)$ & $(0,0005)$ & $(0,0)$ \\
\hline Coef. Persistência & $-0,044$ & 0,047 & 0,04 & 0,11 & 0,17 \\
\hline dos Choques & $(0,54)$ & $(0,0052)$ & $(0,69)$ & $(0,08)$ & $(0,0)$ \\
\hline Retorno da & 0,0048 & 0,000689 & 0,0089 & 0,007 & 0,004 \\
\hline Taxa SELIC & $(0,33)$ & $(0,28)$ & $(0,71)$ & $(0,25)$ & $(0,06)$ \\
\hline Swap & & $\begin{array}{c}6,08 \mathrm{E}-09 \\
(0,80)\end{array}$ & $\begin{array}{c}1,64 \mathrm{E}-8 \\
(0,77)\end{array}$ & $\begin{array}{c}-9,5 \mathrm{E}-10 \\
(0,89)\end{array}$ & $\begin{array}{c}1,60 \mathrm{E}-9 \\
(0,64)\end{array}$ \\
\hline Título cambial & $\begin{array}{c}2,63 \mathrm{E}-08 \\
(0,15)\end{array}$ & $\begin{array}{c}-8,68 \mathrm{E}-10 \\
(0,05)\end{array}$ & $\begin{array}{c}1,03 \mathrm{E}-7 \\
(0,09)\end{array}$ & $\begin{array}{c}1,33 \mathrm{E}-8 \\
(0,06)\end{array}$ & $\begin{array}{c}1,28 \mathrm{E}-08 \\
(0,52)\end{array}$ \\
\hline Mercado à vista & $\begin{array}{c}2,33 \mathrm{E}-08 \\
(0,02)\end{array}$ & $\begin{array}{c}-8,38 \mathrm{E}-10 \\
(0,05)\end{array}$ & $\begin{array}{c}-1,55 \mathrm{E}-8 \\
(0,56)\end{array}$ & $\begin{array}{c}1,49 \mathrm{E}-8 \\
(0,05)\end{array}$ & $\begin{array}{l}1,82 \mathrm{E}-9 \\
(0,0172)\end{array}$ \\
\hline $\mathrm{R}^{2}$ & 0,81 & 0,39 & 0,23 & 0,08 & 0,004 \\
\hline $\mathrm{N}^{0}$ de observações & 124 & 151 & 743 & 259 & 700 \\
\hline \multicolumn{6}{|l|}{ Painel B } \\
\hline Coef. Persistência da & 1,01 & 0,83 & 0,63 & $3,52 \mathrm{E}-6$ & $1,19 \mathrm{E}-6$ \\
\hline Variância Condicional & $(0,0)$ & $(0,0)$ & $(0,08)$ & $(0,41)$ & $(0,50)$ \\
\hline Coef. Persistência & $-0,018$ & 0,047 & 0,02 & 0,78 & 0,74 \\
\hline dos Choques & $(0,78)$ & $(0,0052)$ & $(0,79)$ & $(0,01)$ & $(0,0)$ \\
\hline Retorno da & $-0,000668$ & 0,0341 & 0,0189 & 0,0235 & 0,081 \\
\hline Taxa SELIC & $(0,37)$ & $(0,38)$ & $(0,81)$ & $(0,82)$ & $(0,34)$ \\
\hline Swap & & $4,03 \mathrm{E}-06$ & $1,62 \mathrm{E}-7$ & 0,012 & 0,004 \\
\hline & & $(0,85)$ & $(0,87)$ & $(0,03)$ & $(0,06)$ \\
\hline Título cambial & $\begin{array}{c}2,73 E-9 \\
(0,66)\end{array}$ & $\begin{array}{c}-8,63 \mathrm{E}-19 \\
(0,03)\end{array}$ & $\begin{array}{c}1,04 \mathrm{E}-7 \\
(0,02)\end{array}$ & $\begin{array}{c}-7,5 \mathrm{E}-8 \\
(0,79)\end{array}$ & $\begin{array}{c}1,60 \mathrm{E}-9 \\
(0,41)\end{array}$ \\
\hline Mercado à vista & $\begin{array}{c}-5,34 \mathrm{E}-12 \\
(0,32)\end{array}$ & $\begin{array}{c}-8,98 \mathrm{E}-11 \\
(0,41)\end{array}$ & $\begin{array}{c}-1,35 \mathrm{E}-8 \\
(0,32)\end{array}$ & $\begin{array}{c}1,33 \mathrm{E}-8 \\
(0,52)\end{array}$ & $\begin{array}{c}1,21 \mathrm{E}-7 \\
(0,61)\end{array}$ \\
\hline $\mathrm{R}^{2}$ & 0,82 & 0,49 & 0,42 & 0,51 & 0,63 \\
\hline $\mathrm{N}^{0}$ de observações & 124 & 151 & 743 & 259 & 700 \\
\hline
\end{tabular}

O horizonte da estimação compreende o período de janeiro de 1999 a setembro de 2006. Os dados são diários. A variável dependente é a Volatilidade Condicional da Taxa de Câmbio Nominal. O Painel A apresenta os resultados do modelo GARCH (equações 4 e 5) e o Painel B apresenta os resultados da estimação do modelo IGARCH (equações 6 e 7). Em parêntesis estão informados os $p$-valores. Durante o período de análise foram realizadas 1.174 intervenções. Deste total 526 foram Intervenções à Vista, 483 foram Intervenções via Títulos Cambiais e foram 165 Intervenções via Swaps Cambiais.Usamos como variáveis instrumentais três defasagens da depreciação da taxa de câmbio nominal. 
Table 9: Intervenções do Banco Central e a Volatilidade Condicional da Taxa de Câmbio Nominal: Somando Títulos Cambiais com Swaps Cambiais

\begin{tabular}{lccc}
\hline \multicolumn{4}{l}{ Variável Dependente: Volatilidade Condicional da Taxa de Câmbio Nominal } \\
\hline & Com crises cambiais & \multicolumn{1}{l}{ Sem crises cambiais } \\
\hline \multirow{4}{*}{ Período } & $(\mathrm{C})$ & $(\mathrm{D})$ & $(\mathrm{E})$ \\
& $31 / 05 / 02$ & $01 / 01 / 03$ & $01 / 01 / 04$ \\
& $31 / 12 / 02$ & $31 / 12 / 03$ & $21 / 09 / 06$ \\
\hline Variável & Eq. var. & Eq. var. & Eq. var. \\
independente & & & \\
\hline Constante & $-0,76$ & $-1,16$ & $-1,90$ \\
& $(0,02)$ & $(0,031)$ & $(0,0099)$ \\
Coef. Persistência da & 0,22 & 0,23 & 0,10 \\
Variância Condicional & $(0,0)$ & $(0,0073)$ & $(0,36)$ \\
Coef. Persistência & 0,10 & 0,14 & 0,18 \\
dos Choques & $(0,03)$ & $(0,0033)$ & $(0,01)$ \\
Coef. Assimetria & 0,93 & 0,90 & 0,81 \\
dos Choques & $(0,0)$ & $(0,0)$ & $(0,0)$ \\
Retorno da & $-5,38$ & $-80,64$ & $-30,35$ \\
Taxa SELIC & $(0,61)$ & $(0,0054)$ & $(0,60)$ \\
(Swap+Títulos) & $-0,000102$ & $-2,70 \mathrm{E}-4$ & $-4,81 \mathrm{E}-5$ \\
& $(0,08)$ & $(0,09)$ & $(0,073)$ \\
Mercado à vista & $6,54 \mathrm{E}-05$ & $3,75 \mathrm{E}-5$ & $-7,93 \mathrm{E}-7$ \\
& $(0,26)$ & $(0,19)$ & $(0,06)$ \\
$\mathrm{R}^{2}$ & 0,12 & 0,0 & 0,02 \\
$\mathrm{R}^{2}$ ajustado & 0,10 & 0,03 & 0,019 \\
$\mathrm{~N}^{0}$ de observações & 151 & 259 & 700 \\
\hline
\end{tabular}

O horizonte da estimação compreende o período de janeiro de 1999 a setembro de 2006. Os dados são diários. A variável dependente é a Volatilidade Condicional da Taxa de Câmbio Nominal. Estamos estimando o conjunto de parâmetros: Coeficiente de Persistência da Variância Condicional, Coeficiente de Persistência dos Choques na Variância Condicional, Coeficiente de Assimetria dos Choques na Variância Condicional, a variação da taxa de juros Selic, Intervenções à Vista, Intervenções via Títulos Cambiais mais Swaps Cambias. Em parêntesis estão informados os $p$-valores. Durante o período de análise foram realizadas 1.174 intervenções. Deste total, 526 foram Intervenções à Vista, 648 foram Intervenções via Títulos Cambiais mais Swaps Cambiais. 


\section{CONCLUSÃO}

Analisamos a eficácia das intervenções do Banco Central de Brasil no mercado de câmbio durante o período após a introdução do regime de câmbio flutuante, a partir de janeiro de 1999 até setembro de 2006. Os resultados sugerem que a política de intervenção do câmbio foi eficaz a partir da crise cambial do primeiro semestre de 1999.

Acreditamos que o Banco Central tenha após a crise cambial de 1999, implementado um conjunto de políticas macroeconômicas consistentes que permitiram que as intervenções no mercado cambial sinalizassem melhor para o mercado sua futura política monetária.

Testamos a robustez dos resultados encontrados estimando diferentes modelos de volatilidade condicional da taxa de câmbio nominal. Utilizamos modelos GARCH e IGARCH, e re-estimamos o modelo E.GARCH com diversas especificações. Nossos resultados se mostraram robustos a todos os testes de robustez.

Uma questão interessante, não tratada neste artigo, seria analisar a eficiência das intervenções do Banco Central no mercado cambial. Seria perguntar até que ponto elas se justificam em termos de política macroeconômica, considerando seus altos custos tanto no mercado à vista como no mercado de derivativos de câmbio. Cremos que isto é um tema relevante para futuros trabalhos.

\section{BIBLIOGRAPHY}

Araújo, J. D. P. \& Goldfajn, I. (2004). Suavizando movimentos da taxa de câmbio ou adicionando volatilidade? Um estudo empírico sobre intervenções do Banco Central no mercado de câmbio. Dissertação de mestrado, Pontifícia Universidade Católica do Rio de Janeiro (PUC-Rio).

Beine, M., Lahaye, J., Laurent, S., Neely, C., \& Palm, F. (2006). Central bank intervention and exchange rate volatility, its continuous and jump components. Research Division - Federal Reserve Bank of St. Louis.

Bollerslev, T. (1986). Generalized autoregressive conditional heterocedasticity. Journal of Econometrics, 31:307-327.

Domaç, I. \& Mendonza, A. (2002). Is there room for foreign interventions under inflation targeting framework? Evidence from Mexico and Turkey. Research Papers 58, Central Bank of Turkey.

Dominguez, K. M. (1993). Does central bank intervention increase the volatility of foreign exchange rates. National Bureau of Economic Research: Working Paper 4532.

Engle, R. R. (1982). Autoregressive conditional heterocedasticity with estimates of the variance of United Kingdom inflation. Econometrica, 50(4):987-1007.

Kim, S., Shepard, N., \& Chib, S. (1998). Stochastic volatility: Likelihood inference and comparison with ARCH models. Review of Economic Studies, 65:361-393.

Nelson, D. B. \& CAo, C. Q. (1992). Inequality constraints in the univariate GARCH model. Journal of Business and Economic Statistics, 10:229-235.

Obstfeld, M. (1988). The effectiveness of foreign exchange intervention: Recent experience. National Bureau of Economic Research: Working Paper 2796.

Oliveira, F. N. (2004). O mercado de hedge cambial no brasil: Reação das instituições financeiras a intervenções do banco central. Working Paper do Banco Central do Brasil 89.

Rogoff, K. (1984). On the effects of sterilized intervention. An analysis of weekly data. Journal of Monetary Economics, 14:133-50. 
Sarno, L. \& Taylor, M. P. (2001). Official intervention in the foreign exchange market: Is it effective and, if so, how does it work? Centre Economic Policy Research. Discussion Paper Series 2690.

Vella, F. A. (1993). Simple estimator for simultaneous models with censored endogenous regressors. International Economic Reviews, 34(2):441-457. 